ticides in the United States, comprising 853 comparisons (A. L. Taylor), and a succinct account of the way in which Heterodera rostochiensis is held in check on Long Island by nematicidal treatment (chiefly with dichloropropene), cultural methods and legal regulation, and the use of resistant varieties of potato in fields where the nematode population remains below the level of discovery (W. F. Mai and M. B. Harrison).

The diffusion of ethylene dibromide through soil was shown by F. Call and N. G. M. Hague to be largely determined by soil porosity; relating chemical to bioassay determinations, they found that very low concentrations persist for long periods. H. W. Nolte found only temporary benefit from using 'Vapam' against Pratylenchus in pine nurseries, and $\mathbf{K}$. Raschke showed that reduction of hatching from Heterodera cysts after treatment with 'Trapex' was due not to delayed hatching but to death of larvæ.

Ultrasonic vibrations, tested by L. Kaempfe, gave disappointing results, especially against encysted Heterodera larvæ.

Radiotracer techniques using phosphorus-32 were applied by B. A. Oteifa and D. M. Elgindi to a study of galling in tomatoes by Meloidogyne javanica and its effect on uptake of nutrient, and by F. Sprau and A. Suesz to indicate that Longidorus maximus feeds on the roots of beet and is thus a parasite; and, using carbon-14, were adapted by B. M. Zuckerman to estimate the amount of plant fluid ingested by $a$ single nematode.

At the biennial general meeting on July 27 members of the Society heard an encouraging report from the secretary, Dr. Lindhardt, who was able to show a steady growth in membership over the years:

1957: 141 members from 19 countries; 1959: 179 from 25 countries; 1961 : 218 from 33 countries (of this last total, 166 come from Europe).

An invitation from Dr. John Grainger to hold the seventh symposium at Auchincruive in September 1963 was accepted with enthusiasm, and Prof. Nolte tabled an advance invitation to Aschersleben for 1965. It was decided to issue to members a duplicated. 'Newsletter' under the editorship of Dr. Lindhardt, assisted by a corps of reporters.

A lavish social programme included a civic reception at the Town Hall, a dinner at the Castle of Laarne, and a lunch at the Park Hotel, Lokeren. There was also a programme of daily excursions for non-participating ladies.

Translator-in-chief, displaying equal facility in the three official languages besides his native Flemish, was Mr. R. Kips (secretary).

B. G. Peters

\title{
A NEW LABORATORY FOR RESEARCH ON CREEP
}

$\mathrm{O}$ N July 6 the new Creep Laboratory of the British Electrical and Allied Industries Research Association was opened at Leatherhead by Dr. Charles Sykes, managing director of Thomas Firth and John Brown, Ltd. Its purpose is to carry out an extended programme of long-term co-operative research and investigation on the creep of steels in conditions of high temperature and mechanical stress.

Increase in the overall efficiency of generation of electrical power by steam now turns critically on improving the thermodynamic efficiency by operating at higher temperatures and pressures. The limiting factors in practice are set by materials capable of withstanding these conditions during long periods. The highest temperatures (above $600^{\circ} \mathrm{C}$.) are found in superheater tubes, steampipes and control valves, but conditions are even more onerous in turbine rotors, blades and casings where tolerance to distortion is very small.

Historically, progress in steel development has occurred in three phases. Initially, power-station plant was constructed entirely of plain carbon steel; this was followed by the addition of small amounts of alloying elements which added strength to the steel. Now, in the third phase, special highly alloyed stainless steels are being developed. The cost of such steels is high and is reflected in the great increase in the proportion of cost of steam-raising equipment in modern power stations. Such increases must, in the long run, be offset by increased efficiency, and this can only be judged when full knowledge of the life and reliability of these new steels is available. Creep, which can be defined as permanent deformation of materials arising from continued stress, is of basic importance in this connexion.

The investigation of the properties of high-temperdture steels for power stations was inaugurated as long ago as 1930 by the Steels for High Temperature Committee of the Electrical Research Association. Most of the investigations until recently have been carried out by the Metallurgical Division of the National Physical Laboratory and at the National Engineering Laboratory. In 1957 work was started at the Electrical Research Association to supplement that at the National Physical Laboratory. The National Physical Laboratory is, however, no longer able to cope with the vastly expanded programme, and through the joint efforts of the Committee it has been possible to centre all the work in the new buildings and equipment installed at Leatherhead.

The main Laboratory is $140 \mathrm{ft}$. long and $45 \mathrm{ft}$. wide. It has space for about 250 units for testing creep. Since these units dissipate considerable heat it has been necessary to install air-circulating equipment to maintain a suitable ambient temperature for instrumentation and personnel. The bulk of the units are designed to record either the creep or the time of rupture of standard samples cut and very accurately machined from bars of steel or from fabricated parts. At present there are fifty units of high sensitivity fitted with Martens optical extensometers. These machines are designed particularly for studying the creep behaviour of turbine rotor forgings, blades and casings, and are at present also being used for the creep of metal weld deposits and the parent metal. There are fifty large rupture machines, in which ten specimens can be stressed simultaneously end to end. They do not record the creep but only the time to rupture. They are used to provide long-time design data for high-alloy steel steampipes and superheater tubes. The stress applied to the specimens is varied so as to produce rupture times extending from about 300 to $10^{5} \mathrm{hr}$. Graphs of rupturing time against stress are then used 
to predict the life under the stress conditions found in service. The variation from cast to cast within a particular specification is under investigation.

There are a further fifty dual-purpose creep/rupture units which can be used either as specimen rupture machines or as creep machines using dial gauge extensometers where less-accurate creep measurement is required. They are at present employed in measure. ments on turbine casings. One large machine with 15-ton loading has been installed for rupture-testing of full sections of steampipe.

The temperatures of the specimens are maintained by electric furnaces, the range of temperature of which at present extends from $450^{\circ} \mathrm{C}$. to $700^{\circ} \mathrm{C}$., but can be raised above this temperature when future requirements demand. The furnace temperature is maintained automatically by an electronic controller, to within $\pm 3^{\circ} \mathrm{C}$. up to $600^{\circ} \mathrm{C}$. and to within $\pm 4^{\circ} \mathrm{C}$. above $600^{\circ} \mathrm{C}$. Temperatures of the specimens themselves are measured by means of thermocouples (of which there are three on each specimen) in the high-sensitivity units. The thermocouple readings can be channelled selectively to a central control desk for manual measurement, but during critical periods they can be connected to one of 36 continuous record- ing charts situated in the Laboratory. In the rupture units there are five thermocouples distributed among the ten specimens. These, too, can be channelled to the control desk.

Another important project which is being undertaken in the new Laboratory is the testing to destruction of thick-walled tubes by applying steam pressure for long periods of time at temperatures encountered in service. This enables the creep data obtained in the Laboratory to be correlated with data on actual tubes so that the expected life in practice can be assessed. In testing creep in the Laboratory only a single uni-axial stress is applied whereas a steampipe is subjected to a complex stress system. Four such test rigs have been operating in the Electrical Research Association during the past three years. There are now fifteen rigs.

The data obtained in the new Laboratory will be subject to constant scrutiny as a means of providing more understanding of the mechanism of creep resistance of high-temperature steels. Knowledge of this kind will almost certainly be of benefit in the future development of steels for still higher temperatures, the demand for which is likely to continue for a long time.

\section{CLIMATOLOGY AND CONSERVATION IN MUSEUMS}

$\mathrm{T}$ HE Commission for Museum Laboratories of the International Council of Museums and the International Study Centre for the Preservation and Restoration of Cultural Property have recently undertaken a world-wide inquiry into the subject of environment in relation to conservation. Replies from sixty-four institutions to a questionnaire on the subject, and further study of the situation thus revealed, form the basis of a 46-page report*. In it, museum curators, rather than scientists specializing in conservation, are provided with a useful compendium on the atmosphere and its contaminants, hygrometry, instrumentation and equipment for the control of museum climate. In addition there are several useful reference tables relating to conditions within and outside museums in various parts of the world.

As is proper for documents issued by an international organization, several authors from various European countries have contributed, but the actual publication consists of complete texts in French and in English. Taking into account the polyglot sources of the material, the effort can only be said to have been altogether praiseworthy. Moreover, the fact that the report is written for curators who must be assumed to have little knowledge of the physics involved, must have added to the task. Faced with this require. ment, however, it is unfortunately all too easy to stray away from rigorous scientific exposition for the sake of a tempting analogy. For example, it may be acceptable in the introductory paragraph to compare inanimate objects with human beings in their reaction to the environment: "They live and breathe in the sense that there is continual if imperceptible change arising from their adaptation to the

* International Centre for the Study of the Preservation and the Restoration of Cultural Property, Rome. Works and Publication III: Climatology and Conservation in Museums. (Reprinted from Museum, 13, No. 4, 1960.) Pp. 201-289. (Rome: International Cultural Property, Vla Cavour, 266, 1960. Also available at H.M.S.O.) ambient conditions of the museum"; but, is it wise to persist with: "Some objects have a surprising capacity for adapting themselves to environment apparently without deleterious effect. Thus, a particular piece of wood or bronze may be recovered in remarkable condition after having been conserved for centuries in a swamp or bog; or a certain picture which has been exposed in a damp church may survive the ill-effects beyond all expectation. Let them be brought from their accustomed habitat into a museum, however, and the true state of affairs will soon be manifest, even where the atmosphere is rigorously conditioned"? (p. 243). Again: "The crux of the matter is to be found in the past history of the specimen, its structure and the conditions to which it has already become acclimatised. As is well known. even the best museum conditions can be dangerous for a painted panel that has been normally housed in a cold, damp country house" (p. 253). This may or may not be a phenomenon which is observable under scientific control, but if it is, to imply a conditioning process in the biological sense only helps to perpetuate the notion which is sometimes present among curators that objects, particularly paintings, lose their 'resistance' in the soft environment of the airconditioned gallery and decay, or alternatively, become unfit to withstand uncontrolled conditions.

Where the equilibrium that the object will attain in the museum results in a considerable change in moisture content, there will obviously be undesirable - often catastrophic-volume changes. Special techniques have been developed for dealing with such cases as, for example, water-logged wood. But it is difficult at first to entertain the idea that stabilizing the atmosphere at parameters well within those of the natural cycles can be harmful. Evidence on the alleged phenomenon is unfortunately biased for the simple reason that objects are closely and regularly inspected, once they have entered the museum-but 